\title{
Suppression of HIV-I replication by microRNA effectors
} Christine Chable-Bessia ${ }^{\dagger 1}$, Oussama Meziane ${ }^{\dagger 1}$, Daniel Latreille ${ }^{\dagger 1}$, Robinson Triboulet ${ }^{1}$, Alessia Zamborlini ${ }^{2}$, Alexandre Wagschall ${ }^{1}$, JeanMarc Jacquet ${ }^{3}$, Jacques Reynes ${ }^{3}$, Yves Levy ${ }^{4}$, Ali Saib², Yamina Bennasser*1 and Monsef Benkirane*1

\author{
Address: ${ }^{1}$ Institut de Génétique Humaine CNRS UPR1142, Laboratoire de Virologie Moléculaire, Montpellier, France, ${ }^{2}$ CNRS UMR7151 et \\ Conservatoire National des Arts et Métiers, Paris, France, ${ }^{3}$ Service des Maladies Infectieuses et Tropicales, Centre hospitalier universitaire \\ Montpellier, France and ${ }^{4}$ INSERM, Unite U841, Université Paris 12, Faculté de Médecine, AP-HP, Groupe Henri-Mondor Albert-Chenevier, \\ Immunologie clinique, Créteil, F-94010, France \\ Email: Christine Chable-Bessia - christine.chable-bessia@igh.cnrs.fr; Oussama Meziane - oussama.meziane@igh.cnrs.fr; \\ Daniel Latreille - daniel.latreille@igh.cnrs.fr; Robinson Triboulet - robinson.triboulet@igh.cnrs.fr; \\ Alessia Zamborlini - alessia.zamborlini@univ-paris-diderot.fr; Alexandre Wagschal - alexandre.wagschal@igh.cnrs.fr; Jean- \\ Marc Jacquet - jacquet@chu-montpellier.fr; Jacques Reynes - j-reynes@chu-montpellier.fr; Yves Levy - yves.levy@hmn.aphp.fr; \\ Ali Saib - ali.saib@univ-paris-diderot.fr; Yamina Bennasser* - yamina.bennasser@igh.cnrs.fr; \\ Monsef Benkirane* - monsef.benkirane@igh.cnrs.fr \\ * Corresponding authors †Equal contributors
}

Published: 9 March 2009

Retrovirology 2009, 6:26 doi:10.1186/1742-4690-6-26

This article is available from: http://www.retrovirology.com/content/6/1/26

(c) 2009 Chable-Bessia et al; licensee BioMed Central Ltd.

This is an Open Access article distributed under the terms of the Creative Commons Attribution License (http://creativecommons.org/licenses/by/2.0), which permits unrestricted use, distribution, and reproduction in any medium, provided the original work is properly cited.
Received: 12 February 2009

Accepted: 9 March 2009

\begin{abstract}
The rate of HIV-I gene expression is a key step that determines the kinetics of virus spread and AIDS progression. Viral entry and gene expression were described to be the key determinants for cell permissiveness to HIV. Recent reports highlighted the involvement of miRNA in regulating HIV-I replication post-transcriptionally. In this study we explored the role of cellular factors required for miRNA-mediated mRNA translational inhibition in regulating HIV-I gene expression. Here we show that HIV-I mRNAs associate and co-localize with components of the RNA Induced Silencing Complex (RISC), and we characterize some of the proteins required for miRNA-mediated silencing (miRNA effectors). RCK/p54, GWI82, LSm-I and XRNI negatively regulate HIV-I gene expression by preventing viral mRNA association with polysomes. Interestingly, knockdown of $\mathrm{RCK} / \mathrm{p} 54$ or DGCR8 resulted in virus reactivation in PBMCs isolated from HIV infected patients treated with suppressive HAART.
\end{abstract}

\section{Background}

RNA silencing (RNAi) is a new gene regulatory mechanism conserved from plants to humans. RNAi mediators are small non-coding RNAs (sncRNAs) that function through sequence specific mRNA targeting to either induce their degradation and/or inhibit translation $[1,2]$. In mammals, RNAi is mediated by different classes of small non-coding RNAs including piRNAs, microRNAs and siRNAs [3-5]. MicroRNAs are produced from a primary transcript (pri-miRNA) which is processed in the nucleus by the microprocessor complex containing RNase Drosha and DGCR8. The resulting product or pre-miRNA is exported to the cytoplasm through the exportin-5 pathway. Cytoplasmic pre-miRNA is processed by typeIII RNase Dicer to miRNA/miRNA* duplex of 19 to 25 nucleotides. miRNA/miRNA* is incorporated into the RNA- 
Induced Silencing Complex (RISC) where miRNA* is degraded while miRNA serves as a guide for mRNA targeting [2]. Key components of miRISC are proteins of the Argonaute family (Ago1 to Ago4) that are required for miRNA-mediated silencing $[6,7]$. To ensure mRNA translational inhibition and decay, miRISC, loaded with miRNA and its mRNA targets, associate with proteins involved in mRNA processing [2]. A key factor in this process is the GW182 protein that interacts directly with Argonaute1 (Ago1) [8], and the human homologs of GW182 that interact with Ago1-4 [9]. GW182 orchestrates both mRNA decapping, through the recruitment of p54/RCK that regulates the activity of the decapping enzymes DCP1/DCP2 [10], and mRNA deadenylation by recruiting the CCR4-NOT1 complex [11]. mRNA decapping and deadenylation leads to mRNA decay through the action of XRN1, a 5'-3' exonuclease [10]. Interestingly, RNAi effectors, including miRNAs and their target mRNAs, Ago proteins, GW182, RCK/p54, LSm-1 and DCP proteins co-localize in cytoplasmic structures called GWbodies or P-bodies suggesting that miRNA-mediated silencing occurs at these sites [11-15]. Emerging evidence suggests that miRNA-mediated gene regulation serves as a defence mechanism against both RNA and DNA viruses in mammals [16-20]. The present study was designed to explore physical and functional interaction between effectors of miRNA-mediated silencing and HIV-1 replication.

\section{Results and discussion}

To investigate whether RNAi effectors regulate HIV-1 replication, we analyzed virus replication in cells where expression of RNAi effectors was reduced using specific siRNA. HeLa cells were transfected with siRNA specific to RCK/p54, GW182, LSm-1 or XRN1. As controls, HeLa cells were transfected with scrambled siRNA (Scr) or CDK9 specific siRNA and subsequently infected with HIV1 (Figure 1a). Knockdown of RCK/p54, GW182, LSm-1 and XRN1 enhanced virus replication by up to 10 fold (Figure 1b). As we have previously shown, knockdown of Drosha [21] and DGCR8 (Figure 1b), the two subunits of the microprocessor complex, increased virus production while knockdown of the CDK9 subunit of the PTEFb complex that is required for viral gene expression, reduced HIV-1 production (Figure 1b). Interestingly, analysis of HIV-1 cytoplasmic mRNA distribution on glycerol gradient showed that knockdown of RCK/p54 shifted HIV-1 mRNA from the non-polysomal fraction to polysomes as compared to control siRNA transfected cells (Figure 2, upper panel). As control, we analyzed the distribution of endogenous mRNA expressed from a gene encoding Hdm2. Knockdown of RCK/p54 did not affect Hdm2 mRNA distribution (Figure 2, lower panel). These experiments show that GW182, RCK/p54, LSm-1 and XRN1, factors required for RNAi, are repressors of HIV-1 gene expression that act by preventing HIV-1 mRNA translation.

We next investigated the physical interaction between RNAi effectors and HIV-1 mRNA. 293 cells were mock transfected or transfected with combinations of pNL4-3, Myc-Ago2, a central component of the RISC complex, or its RNA-binding mutant Myc-Ago2PAZ9 constructs as indicated in figures 3 and 4 . First, we verified that MycAgo2 and Myc-Ago2PAZ9 were equally expressed (Figure 3a). Second, cytoplasmic extracts were prepared, and a fraction was used for total RNA extraction while the rest was subjected to immunoprecipitation using anti-Myc antibody to purify Myc-Ago2 associated mRNP. Both total RNA (Figure 3b, left panels) and Myc-Ago2 associated RNA (Figure 3b, right panels) were reverse transcribed and subjected to PCR amplification using oligonucleotides specific for HIV-1 TAR RNA (a structured motif associated with all HIV-1 mRNAs) or HIV-1 unspliced mRNA, Hdm2 mRNA or GAPDH mRNA. PCR analysis of total RNA showed that equal amounts of HIV-1, Hdm2 and GAPDH mRNAs were present in all samples (Figure 3b, left panels). HIV-1 mRNAs (both TAR and unspliced) were associated with Myc-Ago2, but not with Myc-Ago2PAZ9 mutant (Figure $3 \mathrm{~b}$, right panels). In agreement with the results shown in figure 2, Hdm2 mRNA was not detected in Myc-Ago2 mRNPs, suggesting that under these conditions Hdm2 is not regulated by RNAi. A similar experiment was performed to analyze the association of HIV-1 multispliced mRNA with Myc-Ago2 mRNPs. The RT-PCR reactions were performed in the presence of 32P- $\alpha$ ATP and were analyzed by autoradiography (Figure 3c). HIV-1 multispliced mRNAs associated with Myc-Ago2 (compare lane 3 to 2) and weakly with Myc-Ago2PAZ9 (compare lane 4 to lanes 3 and 2). Co-localization of HIV-1 mRNA and effectors of RNAi such as Ago2 and RCK/p54 within the P-bodies was also observed by immunofluorescence using HIV-1 containing MS2 binding sites and MS2-GFP constructs (Figure 4). Indeed, HIV-1 mRNAs visualized through their binding to MS2-GFP colocalized with endogenous RCK/p54 and ectopically expressed MycAgo2 (Figure 4). Our results show that HIV-1 mRNAs physically associate with Ago2, a central component of RISC, and co-localize with cellular proteins required for miRNA-mediated silencing such as RCK/p54 and Ago2 in P-bodies. We observed that all HIV-1 mRNA species associated with RISC. Accordingly, Huang et al. had identified 5 cellular miRNAs able to target the 3'UTR sequence present in all HIV-1 mRNAs [22]. Additionally, other cellular miRNAs able to target regions out side the 3'UTR may also participate [23].

Emerging evidence suggests the physical and functional interactions between P-bodies and the viral life cycles [24]. Viral mRNA trafficking through P-bodies may repre- 
a)

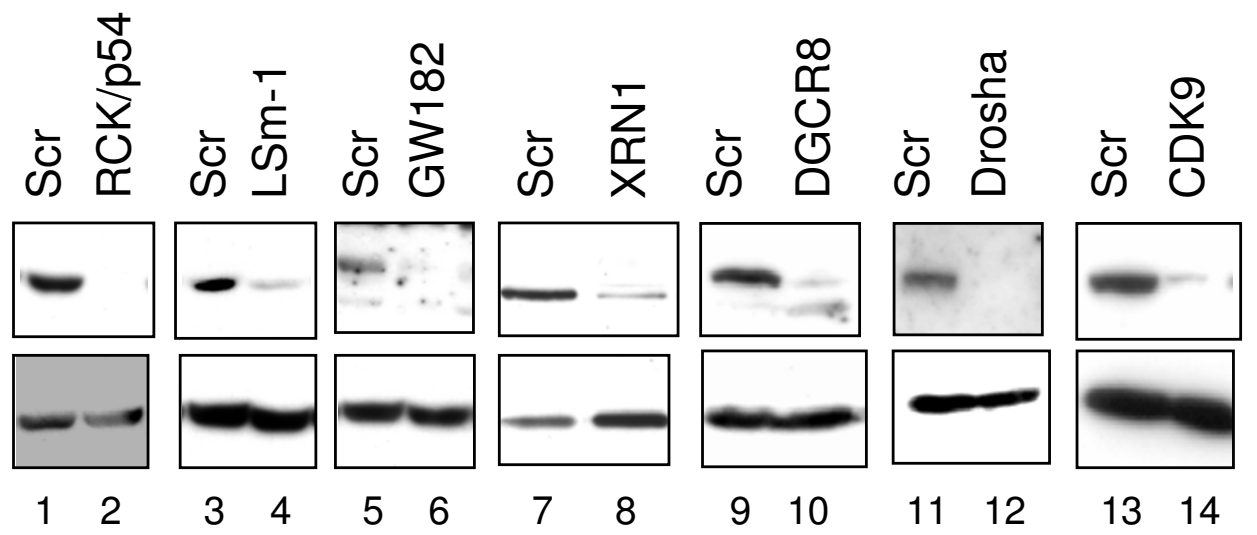

b)

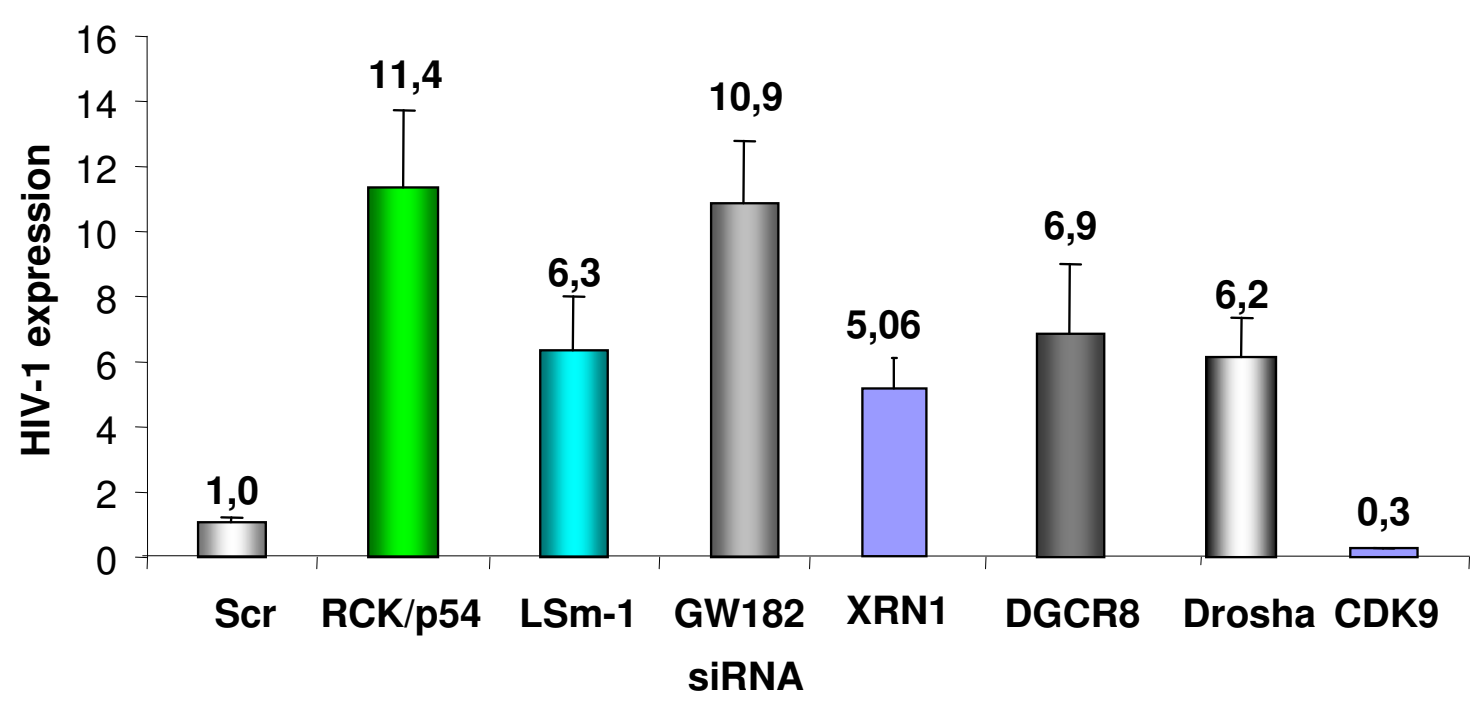

Figure I

miRNA effectors are repressors of HIV-I replication. HeLa cells were transfected with siRNA as indicated. 48 hours post transfection, cells were analyzed for RCK/p54, LSm-I, GWI82, XRNI, DGCR8, DROSHA and CDK9 expression by Western blotting (a), or infected with a single round infectious virus (HIV-I-VSV-luc $200 \mathrm{ng} / \mathrm{ml}$ ) and cell extracts were measured for luciferase activity 48 hours after infection (b). Results are presented as fold HIV production relative to Scr transfected cells, and data are representative of three independent experiments.

sent a pool of translationally repressed viral transcripts otherwise used for efficient packaging or formation of viral-replication complexes. Indeed, yeast retrotransposons Ty1 and Ty3 mRNA associate with P-bodies, and this association is required for efficient retrotransposition [25-27]. In the case of BMV (Brome Mosaic Virus), formation of the virus replication complex occurs in P-bodies [28]. In addition, P-bodies may also function in host defences against viruses and transposable elements. Indeed, the cellular factors APOBEC 3G (A3G) and 3F
(A3F), which are viral restriction factors, are found to accumulate in P-bodies $[29,30]$. It has been suggested that A3G and A3F mediated HIV-1 restriction may involve viral mRNA targeting to P-bodies leading to their translational inhibition [30]. We, therefore, asked whether Pbodies are positive or negative regulators of HIV-1 replication. Thus, we analyzed HIV-1 replication in cells where Pbodies were disrupted by knocking down RCK/p54 or LSm-1 [31]. HeLa CD4+ cells were transfected with RCK/ p54 or LSm-1 specific siRNA or control siRNA. Forty eight 

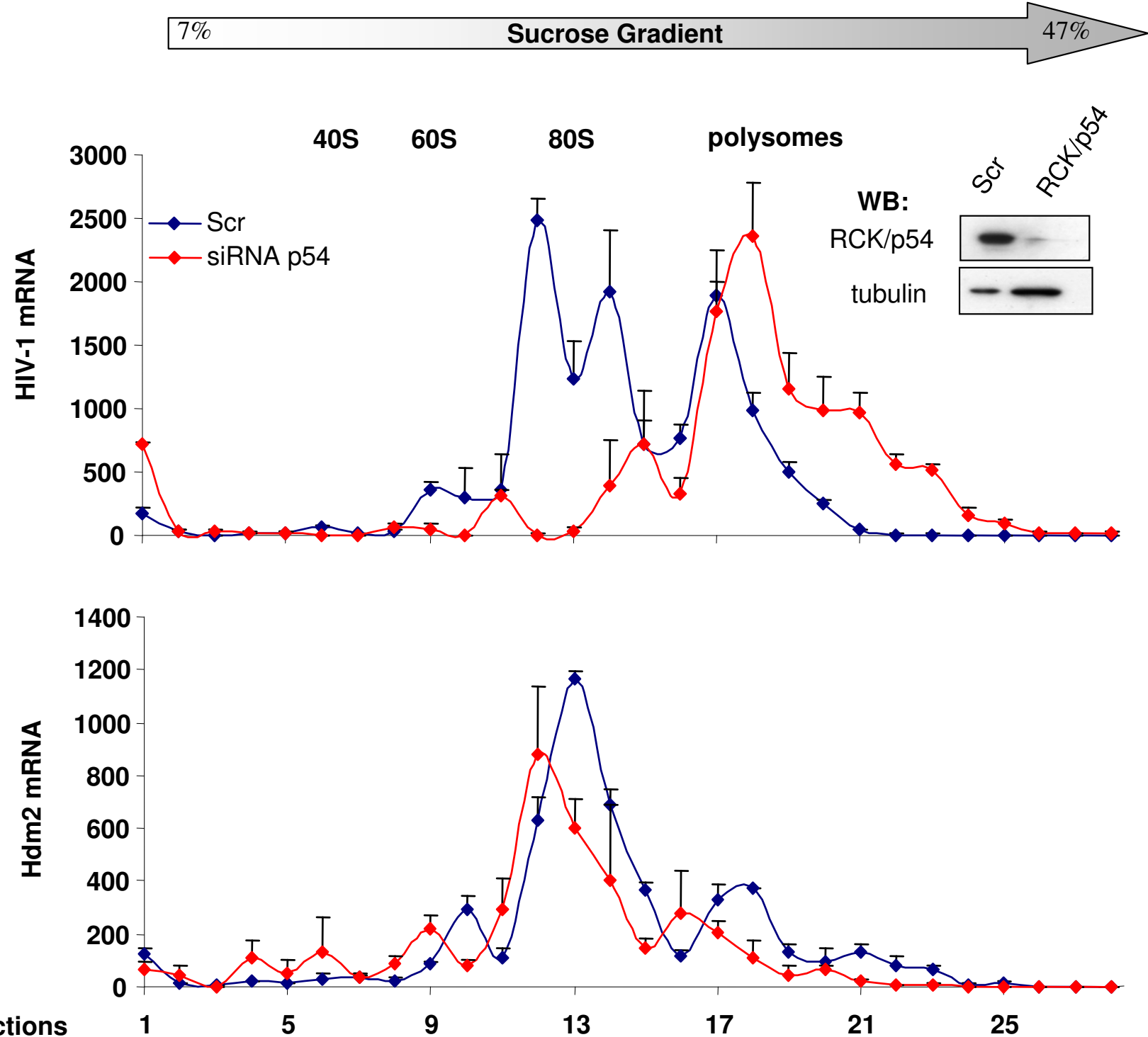

\section{Fractions}

5

13

17

25

\section{Figure 2}

RCK/p54 restricts HIV-I mRNA association with polysomes. Cytoplasmic extracts from HeLa cells that were transfected with the indicated siRNA and infected with HIV-I-VSVG-luc were run on glycerol gradient (7\% to $47 \%)$. Fractions were collected and their RNA contents were monitored by measuring absorbance at $254 \mathrm{~nm}$. HIV-I mRNA (top panel) and Hdm2 mRNA (lower panel) were quantified in all the fractions by Q-RT-PCR using specific oligonucleotides.

hours later, cells were infected with equal amounts of HIV-1 viral particles (as measured by p24 assay). HIV-1 p24 antigen was measured in cell culture supernatant 48 hours post-infection. As shown in figure 5b, knockdown of RCK/p54 or LSm-1 results in enhanced virus production as compared to infection of control siRNA transfected cells. To assess the infectivity of the produced viruses, an equal volume of supernatant from Scr, RCK/p54 and LSm-1 siRNAtransfected cells was used to infect HeLa $\mathrm{CD} 4+$ cells, and p24 release in the culture supernatant was measured 48 hours later (Figure 5c). Virus infectivity cor- related with the amount of p24 produced (Figure 5b) showing that virions produced in RCK/p54 and LSm-1 knocked down cells are fully competent for replication and have no defect in steps such as RNA packaging. Since the knockdown of RCK/p54 and LSm-1 was shown to result in the disruption of P-bodies, we concluded from these experiments that accumulation of HIV-1 mRNA in P-bodies limits virus replication.

Next, we asked whether A3G-mediated HIV-1 restriction requires effectors of miRNA-mediated mRNA transla- 
a)

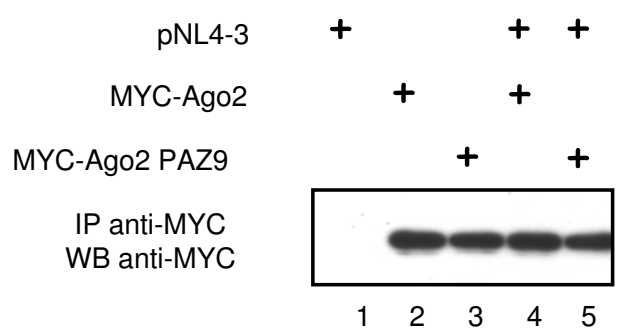

b)

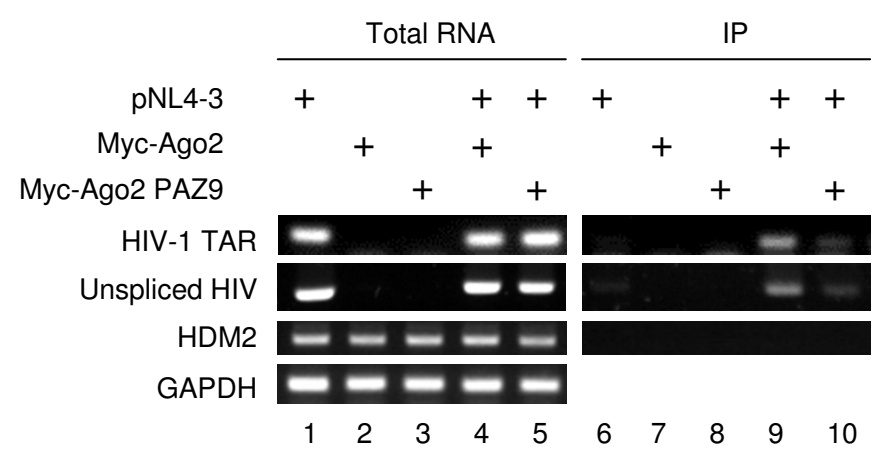

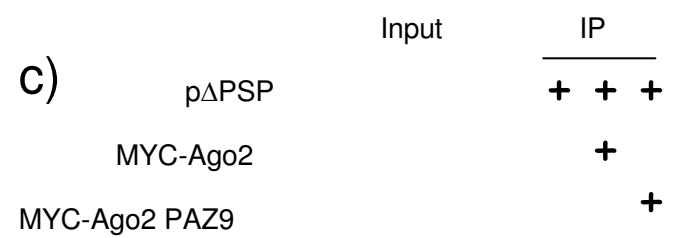

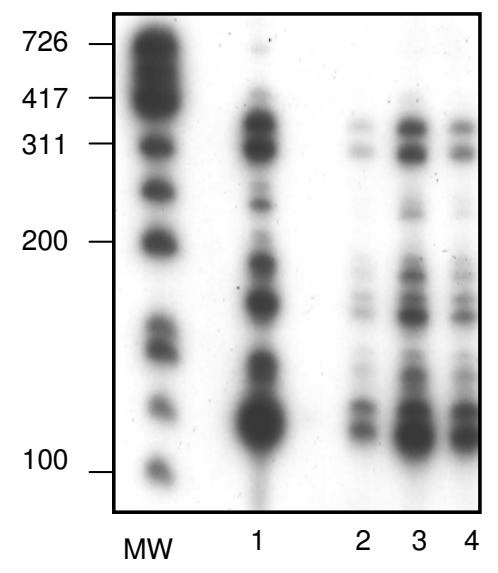

Figure 3

HIV-I mRNAs associate with Argonaute 2. 293 cells were transfected with HIV-I molecular clone pNL4-3, Myc-Ago2 or Myc-AgoPAZ9 as indicated. 48 hours later cells were harvested and cytoplasmic extracts were prepared. Total RNA was purified from a fraction of harvested cells while the rest was subjected to immunoprecipitation using anti-Myc antibody. After washing, a fraction was used to analyze the amount of Myc-Ago2 and Myc-Ago2PAZ9 immunoprecipitated by Western blotting (a), and the rest of the Myc-IPs was used for RNA extraction. HIV-I mRNAs (TAR and unspliced), Hdm2 and GAPDH mRNA were quantified from total RNA (b, left panel) or from Myc immunoprecipitated mRNPs (b, right panel) by RT-PCR using specific oligonucleotides. c) Experiment was performed as in fig 3 except that 293 cells were transfected with HIV-I $\triangle P S P$ which contains a partial gag/pol deletion but retains all the mRNA splicing sites [66], and 32P-labelled nucleotides were used in the PCR reaction. PCR products were visualized by autoradiography.

tional inhibition. Thus, we compared A3G-mediated HIV1 restriction in cells where RCK/p54 or LSm-1 expression was reduced compared to control cells. HeLa cells were transfected with control siRNA or siRNA specific for RCK/ p54 or LSm-1 (Figure 6, right panel). Forty-eight hours later, cells were transfected with an HIV-1 molecular clone lacking the vif gene (pNL4-3 $\Delta$ vif) either alone or with wild-type A3G or A3G mutant lacking antiviral activity (A3Gdm). HIV-1 p24 antigen was measured in culture supernatant 48 hours post-transfection. Interestingly, knock down of RCK/p54 or LSm-1 enhanced HIV-1 production regardless of A3G (Figure 6, left upper panel). Similarly, A3G but not A3Gdm reduced virus production regardless of RCK/p54 or LSm-1 expression (Figure 6, left upper panel). These results suggested that RCK/p54 or LSm-1 and A3G -mediated HIV-1 repression involves different mechanisms. We then analyzed the infectivity of
HIV-1 produced from siRNA transfected cells. Equal amounts of p24 were used to infected HeLa CD4+ cells, and HIV-1 p24 antigen was measured in culture supernatant 48 hours post-infection. As shown in figure 6 (lower panel), virus produced in Scr siRNA transfected cells in the presence of A3G showed lower infectivity than those produced in its absence or in the presence of A3Gdm. Similar HIV-1-restriction activity of A3G was observed when the virus was produced in RCK/p54 or LSm-1 knocked down cells. This experiment showed that A3G-mediated HIV-1 restriction is independent of RNAi effectors RCK/p54 and LSm-1 and does not require P-bodies.

Taken together, our results show a physically repressive interaction between RNAi effectors and HIV-1 mRNA. Since cellular miRNAs were shown to play a role in HIV-1 latency [22], we asked whether RCK/p54, which is 


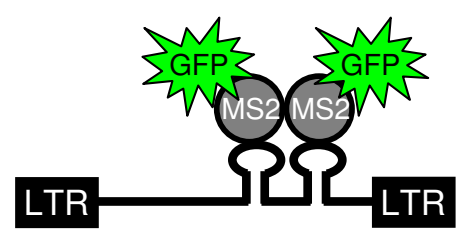

24 MS2 binding sites
Hoechst
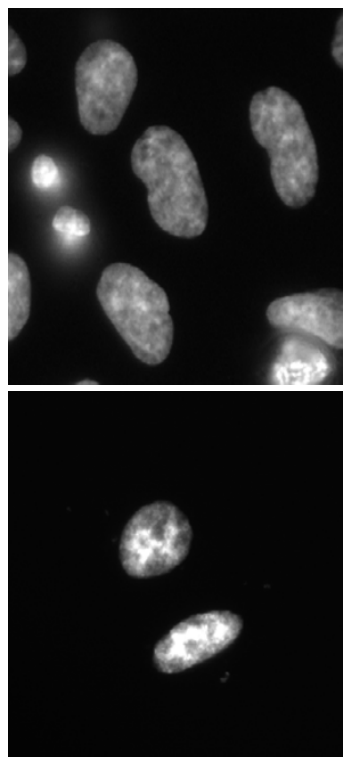

MS2-GFP-NLS
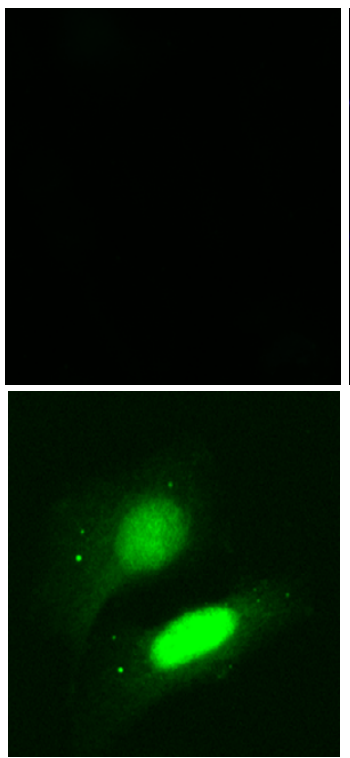

RCK/p54
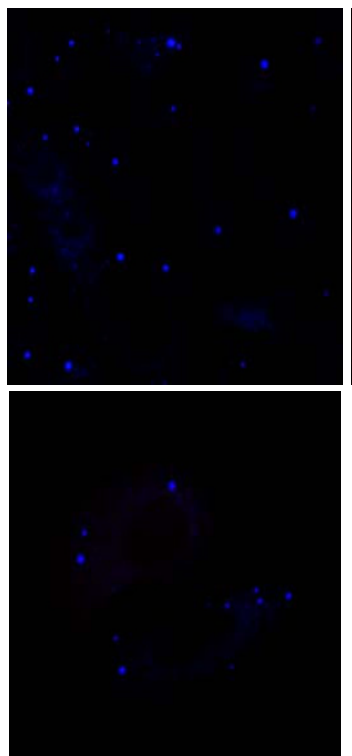

Myc-Ago2
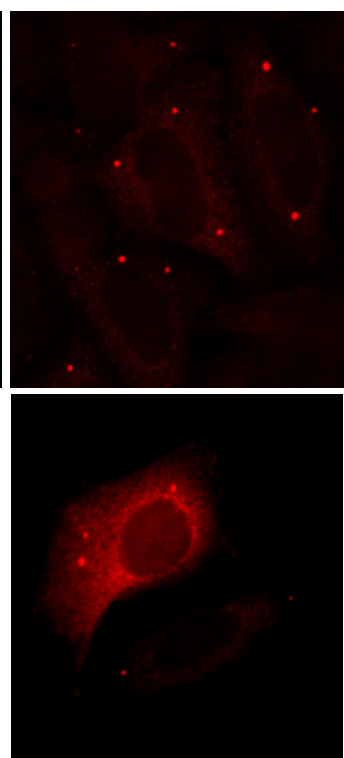

Merge

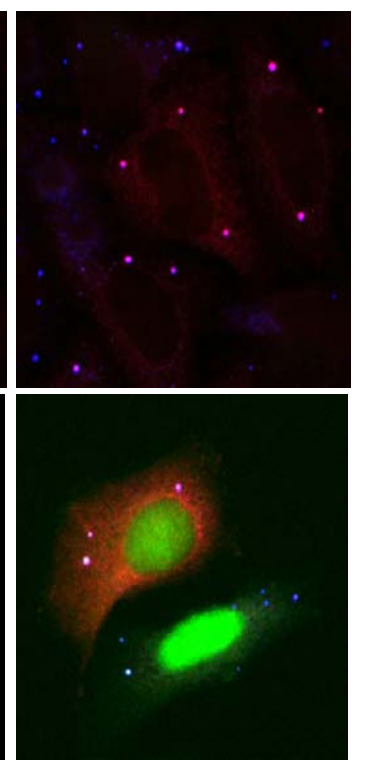

Figure 4

HIV-I mRNA co-localizes with RCK/p54 and Ago2. HeLa cells were transfected with Myc-Ago2 expression vector either alone (top panels) or co-transfected with HIV-I vector containing 24 repeats of MS2 binding sites and MS2-GFP expression vectors [64,65] (lower panels). Endogenous RCK/p54 and transfected Myc-Ago2 were visualized using specific primary antibodies and appropriate secondary antibodies coupled with Cy5 (shown in blue) and Cy3 (red) respectively. HIV-I RNA bound to MS2-GFP is shown in green. Green, blue and red merged images are shown.

required for miRNA-mediated mRNA translational inhibition, contributes to HIV-1 silencing in vivo. Thus, PBMCs isolated from 3 HAART-treated HIV-1-infected patients with undetectable viremia were transfected with control siRNA or with siRNA specific for Drosha, DGCR8 or RCK/p54. Transfected cells were co-cultured with PHA/ IL2-activated PBMCs isolated from healthy donors. Virus production was monitored every 3 days by measuring p24 antigen in the culture supernatant (Figure 7). As we have previously shown, knockdown of Drosha resulted in virus reactivation in PBMCs isolated from 3 HAART-treated HIV-1-infected patients [21]. Remarkably, viral replication from its natural reservoir resumed also when DGCR8 or RCK/p54 was silenced. No virus was isolated from control siRNA transfected PBMCs suggesting that virus production observed in Drosha, DGCR8 and RCK/p54 knock down was not due to actively infected PBMCs relieved from drug pressure. These results show that endogenous levels of Drosha, DGCR8 and RCK/p54 contribute to HIV1 latency and/or its maintenance in infected patients.

\section{Conclusion}

The outcome of HIV-1 infection results from complex interactions between viral components and host cell factors [32-35]. In most cases, HIV-1 successfully hijacks cellular pathways and bypasses restriction factors for optimal replication leading to continuous rounds of infection, replication, and cell death. Continuous viral replication causes the loss of CD4+T cells and progression to immunodeficiency in infected individuals. HAART treatment revealed the existence of a pool of resting memory CD4+ $\mathrm{T}$ cells harbouring integrated, but silent HIV-1 provirus [36,37]. This latent reservoir is believed to be the major obstacle for virus eradication by HAART. Therefore, it is critical to understand how HIV-1 latency is established and maintained [38]. Post-integration latency takes place 
a)

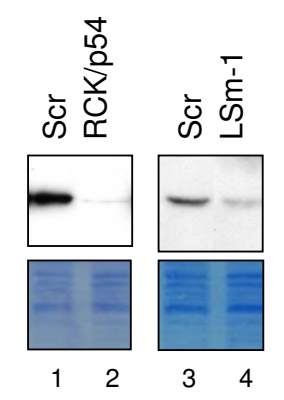

b)

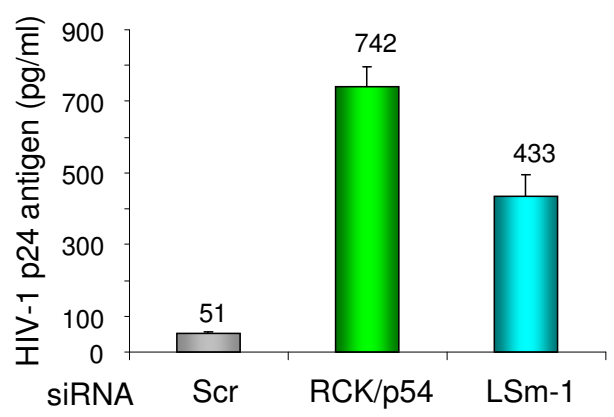

c)

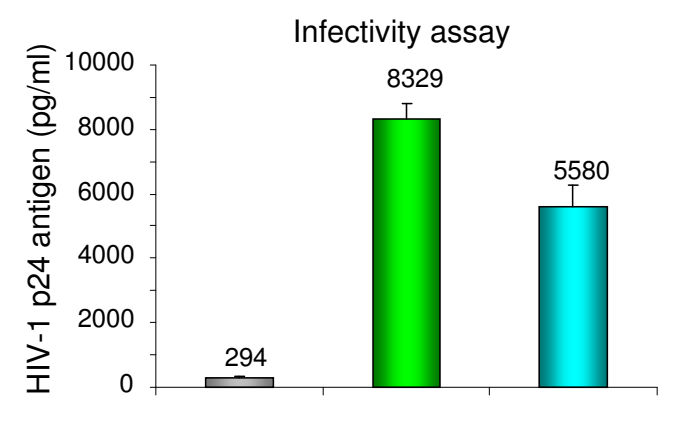

\section{Figure 5}

Disruption of P-bodies through knockdown of RCK/p54 and LSm-I leads to enhanced production of infectious HIV-I virions. HeLa CD4+ cells were transfected with siRNA as indicated. 48 hours post transfection cells were analyzed for RCK/p54 and LSm-I expression by Western blotting (a) and infected with equal amounts of HIV-I (200 ng/ml). b) Virus production was monitored 48 hours post infection by measuring P24 antigen in culture supernatant. c) To analyze the infectivity of new progeny virions, equal volumes of supernatant from siRNA transfected Hela CD4+cells were used to re-infect HeLa CD4+ cells. P24 antigen was measured in culture supernatant 48 hours post infection.

at both transcriptional and post-transcriptional levels [39]. Transcriptional latency involves different mechanisms ranging from integration position effect [40-42], limitation in transcription factors [43-46], establishment of chromatin repressive marks and recruitment of chromatin silencers [47-51]. Post-transcriptional silencing involves defects in mRNA export and translation [52-54]. All together, these studies show that HIV-1 post-integration latency is a multi-factorial process. In the present study, we show that HIV-1 gene expression is additionally regulated by the miRNA pathway. HIV-1 mRNA associates with components of the RISC complex by a mechanism that does not involve APOBEC3G, but does need sncRNAs. Accordingly, it has been recently shown that the suppressor of RNAi P19 from tomato bushy stunt virus, known to bind and sequester sncRNAs including miRNA, enhances HIV-1 replication [55]. Additionally, the RNAi suppressor function of HIV-1 Tat [56] could be complemented by VP35 from Ebola virus [57] and the NS3 protein of rice hoja blanca virus through sequesteration of small non-coding RNAs [58]. HIV-1 mRNAs associated with RISC are sequestered in the non-polysomal fraction, thereby preventing translation. In agreement with two previous reports $[19,21,22]$, we show that knockdown of $\mathrm{RCK} / \mathrm{p} 54$, a protein required for miRNA-mediated silencing, led to virus reactivation from PBMCs isolated from HIV-1 infected patients who were undergoing suppressive HAART.
A challenge in AIDS treatment is the need to activate latent viral reservoirs in order to eradicate these viruses through HAART. In this respect, targeting the miRNA processing pathway could offer a strategy that could be exploited to activate latent viral reservoirs, for instance, during HAART. Several molecules have been used to reactivate viral reservoirs [59]. However, none of these approaches provides the sequence specific targeting that can be achieved using siRNA. Recent data suggest that siRNA can be used therapeutically in vivo in certain mouse disease models [60] and more recently in non-human primates $[61,62]$. It remains to be explored whether, as suggested here, the in vivo targeting of miRNA-effectors using siRNA can assist in activating latent $\mathrm{HIV}-1$ reservoirs for eradication by HAART.

\section{Methods \\ Constructs}

HIV-1 molecular clone pNL4-3 $\Delta$ vif and expression plasmids for APOBEC3G were gift from Olivier Schwartz (Pasteur, France). APOBEC3G H65R/H257R mutant was previously described [63]. HIV-1 vector containing MS2 binding sites and MS2-GFP expression plasmids [64,65] were gift from Alessandro Marcello (ICGEB. Trieste, Italy) and Edouard Bertrand (IGMM. Montpellier, France)

\section{Transfections}

PBMCs were transfected with siRNA or miRNA using the Nucleofector II Device with the appropriate Nucleofection 

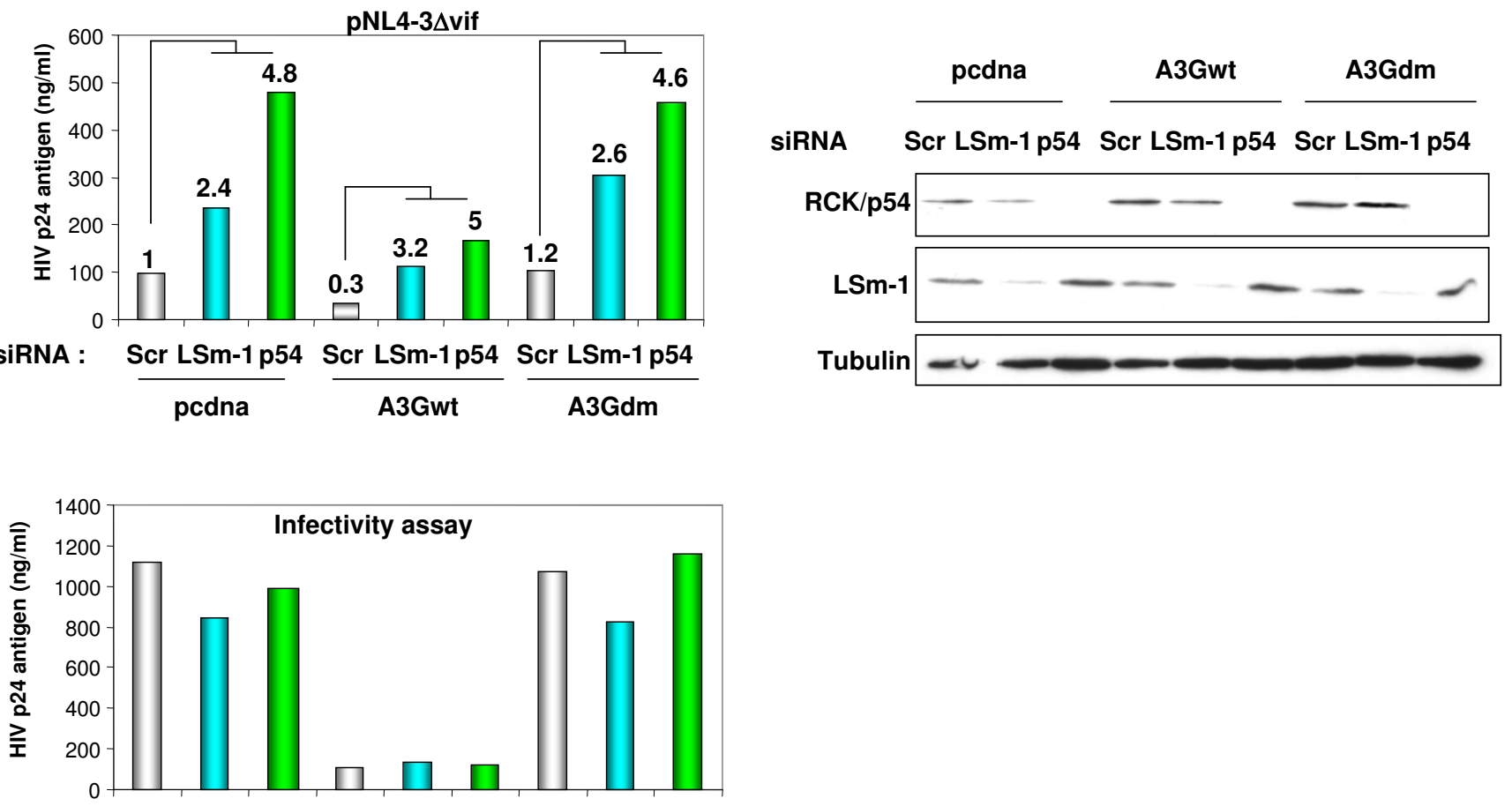

Figure 6

RNAi effectors and APOBEC 3G-mediated HIV-I repression involve different pathways. HeLa CD4+ cells were transfected with the indicated siRNA. 48 hours later cells were analyzed for RCK/p54 and LSm-I expression (right panel) or co-transfected with I $\mu$ g of pNL4-3 $\Delta$ vif (lacking vif gene) and pcDNA or expression vectors for wild-type APOBEC3G or APOBEC3G double mutant lacking both deaminase and antiviral activity, A3G H65R/H257R [63]. HIV-I production was measured 24 hours post-transfection in culture supernatant by quantifying p24 antigen (top left panel). Numbers on the top of the columns are fold increase relative to the respective Scr. Numbers on the top of Scr samples in A3Gwt and A3Gdm represent fold increase relative to Scr in pCDNA transfected cells. Infectivity assay was performed using equal amounts of p24 antigen to infect HeLa CD4+ cells. HIV-I p24 antigen was measured 48 hours post infection (lower left panel). A representative experiment out of five is shown.

solution according to the manufacturer's instructions (Amaxa). siRNA corresponding to DGCR8 (5'-CAUCGGACAAGAGUGUGAU(dTdT)-3'), Drosha (5'-CGAGUAGGCUUCGUGACUU(dTdT)-3'), RCK/p54 (5'GCAGAAACCCUAUGAGAUUUU(dTdT)-3'), LSm-1 (5'GUGACAUCCUGCCACCUCACUU(dTdT)-3'), GW182 (5'-UAGCGGACCAGACAUUUCU(dTdT)-3'), XRN1 (5'AGA UGA ACU UAC CGU AGA A(dTdT)-3') and CDK9 (5'-CCAAAGCUUCCCCCUAUAATT(dTdT)-3') were synthesized (MWG). Expression level of knock down proteins was analyzed by Western blotting 48 hours after transfection. Briefly, cell-extracts were resolved on SDSPAGE gels. Proteins were transferred to PVDF membrane by semi-dry electroblotting and probed overnight at $4{ }^{\circ} \mathrm{C}$ with the primary antibody (anti-Drosha, LSm1, GW182 (Abcam), DGCR8 (Proteintech Group), anti-RCK/p54 (Bethyl)or anti-CDK9 (Santa Cruz), washed and incubated with the appropriate secondary antibody (Amersham) for 1 hour. Proteins were visualized by chemiluminescence according to the manufacturer's protocol (Pierce).
PBMC isolation and co-culture assay for virus production Peripheral blood mononuclear cells of HIV-1 infected patients were isolated by lymphocyte separation medium density centrifugation (Lonza). PBMCs from healthy donors were pre-activated using $5 \mu \mathrm{g} / \mathrm{ml}$ PHA (phytohemagglutinin-P, DIFCO)/10 U/ml IL-2 (interleukin-2, Roche) for 72 hours. They were then washed once with PBS and once with RPMI medium before co-culture assay. siRNA transfected HIV-infected PBMC $\left(10^{6} \mathrm{cells} / \mathrm{ml}\right)$ were co-cultured with pre-activated PBMC $\left(10^{6} \mathrm{cells} / \mathrm{ml}\right)$ from the same healthy donor in the presence of $10 \mathrm{U} / \mathrm{ml} \mathrm{IL-2.}$ The culture medium was collected every 3 or 4 days. Fresh pre-activated healthy PBMCs were added to the culture every 7 days. Viral production was measured by quantifying the amounts of p24 in the culture medium using an ELISA kit (Ingen).

\section{Pseudotyped virion production and single-round infections} The plasmid pNL4-3-env-Luc ${ }^{+}$harboring a luciferase gene (obtained from the NIAID AIDS Reagent Program) was co-transfected with the envelope plasmid pMD.2G encod- 


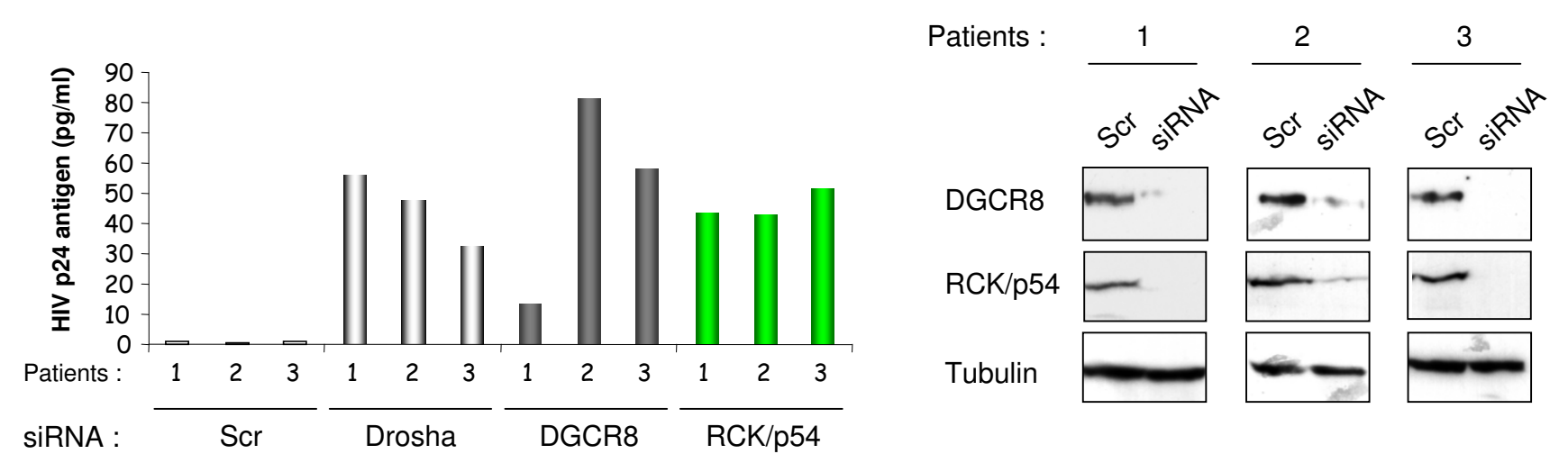

Figure 7

Implication of RNAi in HIV-I latency. PBMCs were isolated from three patients undergoing active HAART. Isolated PBMCs were transfected with the indicated siRNA and either analyzed for RCK/P54, DGCR8 and DROSHA expression by Western blotting 48 hours after transfection (right panel) or co-cultured with activated PBMCs obtained from healthy donors. Virus replication was monitored every 3 to 4 days post co-culture by measuring p24 antigen in culture supernatant. Shown is the amount of p24 antigen at day 15 post co-culture. No virus was isolated from Scr transfected-PBMCs for up to 27 days.

ing the G protein of vesicular stomatitis virus (VSV.G) into human embryonic kidney cells-293T. The virions, named HIV-1VSV-Luc, were collected and filtered using $0.45 \mu \mathrm{m}$ filters 48 hours post-transfection. HeLa or HeLa CD4+ cells were infected over-night at $37^{\circ} \mathrm{C}$, washed and resuspended in DMEM containing 10\% FCS. Virus production was monitored in culture supernatant by measuring p24 antigen (Ingen) and by following luciferase activity according to the manufacturer's instructions (Promega).

\section{Cytoplasmic extracts analysis on sucrose gradients}

To isolate cytoplasmic extracts, cells were lysed for 10 minutes in buffer B (5 mM Tris- $\mathrm{HCl} \mathrm{pH} 7.4,1.5 \mathrm{mM} \mathrm{KCl}$, $2.5 \mathrm{mM} \mathrm{MgCl}_{2}, 0.5 \% \mathrm{NP} 40$ and protease inhibitor). Nuclei were pelleted by centrifugation for 10 minutes at $10,000 \mathrm{rpm}$. $2 \mathrm{mg}$ of cytoplasmic extracts were loaded on a $7-47 \%$ sucrose gradient. Briefly, 5 layers of 7 to $47 \%$ sucrose were prepared in sucrose buffer $(20 \mathrm{mM}$ Tris- $\mathrm{HCl}$ pH7.4, $80 \mathrm{mM} \mathrm{NaCl}, 5 \mathrm{mM} \mathrm{MgCl}$, $1 \mathrm{mM}$ DTT and protease inhibitors) and diffused at $4^{\circ} \mathrm{C}$ for 16 hours to obtain a linear sucrose gradient. $2 \mathrm{mg}$ of cytoplasmic extracts were loaded on the top of the column, and centrifuged for 3 hours at 36,000 rpm in a SW41Ti rotor. After ultracentrifugation, 28 fractions were collected and OD at $254 \mathrm{~nm}$ was measured in each fraction using a Nanodrop apparatus (Labtech).

\section{RNA immunoprecipitation}

293 cells were grown in $60 \mathrm{~mm}$ dishes and transfected with the indicated plasmids using calcium-phosphate. Cells were harvested 48 hours after transfection, lysed for 15 minutes in RIP buffer (20 mM Hepes, pH 7.5, 150 mM
$\mathrm{NaCl}, 2.5 \mathrm{mM} \mathrm{MgCl}_{2} \times 6 \mathrm{H}_{2} \mathrm{O}, 250 \mathrm{mM}$ sucrose, $0.05 \%$ NP40, 0.5\% Triton X-100) containing RNASIN (Promega) and $1 \mathrm{mM}$ DTT, and centrifuged to pellet debris. Supernatants were incubated overnight with mouse anti-Myc mAb 9E10 (Amersham) at $4{ }^{\circ} \mathrm{C}$ followed by 2 hours incubation with protein G-Sepharose. Immunoprecipitates were washed with RIP buffer, and nucleic acids were extracted with phenol/chloroform/isoamyl alcohol, isopropanolprecipitated, ethanol-washed and resuspended in RNasefree water. Total RNA was DNase I treated and reversetranscribed using SuperScript First-Strand Synthesis System for RT-PCR (Invitrogen). RT products were PCRamplified using either GAPDH (GAPDH forward: GTA TTG GGC GCC TGG TCA CC; reverse: CGC TCC TGG AAG ATG GTG ATG G), HIV-1 (HIV-1 forward: TAG TGT GTG CCC GTC TGT T; reverse: CTC TGG TTT CCC TTT CGC TTT C or Gag-reverse: GAT GGT TGT AGC TGT CCC AG for unspliced HIV RNA), or HDM2 specific oligonucleotides (HDM2 forward: GTA CCT GAG TCC GAT GAT TCC; reverse: ACC TAC TGA TGG TGC TGT AAC). PCR products were resolved on $1.5 \%$ agarose/TAE gels containing ethidium bromide. In vivo splicing assay and oligonucleotides BSS and SJ4.7A have been described [66]

\section{Competing interests}

The authors declare that they have no competing interest.

\section{Authors' contributions}

CBC, OL and LD carried out most experiments. TR initiated and performed the experiments shown in figures 3 and 4. AZ participated in experiments analyzing the involvement of APOBEC3. WA, JJM, RJ, LY, and SA partic- 
ipated in some of the experiments such as isolation of PBMCs from HIV-1 infected patients. BY and BM directed, supervised and wrote the manuscript.

\section{Acknowledgements}

We are grateful to Kiernan R, Jeang KT, Emiliani S, and Voinnet $O$ for helpful discussions and for critically reading the manuscript. Work in MB's laboratory was supported by ANRS, SIDACTION, ANR and FRM. OM was supported by fellowship from "infectiopôle grand sud". DL was supported by ANRS scholarship. AZ was supported by SIDACTION fellowship.

\section{References}

I. Brodersen P, Sakvarelidze-Achard L, Bruun-Rasmussen M, Dunoyer $P$, Yamamoto YY, Sieburth L, Voinnet O: Widespread translational inhibition by plant miRNAs and siRNAs. Science 2008, 320: $1185-1190$.

2. Filipowicz W, Bhattacharyya SN, Sonenberg N: Mechanisms of post-transcriptional regulation by microRNAs: are the answers in sight? Nat Rev Genet 2008, 9:102-I I4.

3. Tam OH, Aravin AA, Stein P, Girard A, Murchison EP, Cheloufi S, Hodges E, Anger M, Sachidanandam R, Schultz RM, Hannon GJ: Pseudogene-derived small interfering RNAs regulate gene expression in mouse oocytes. Nature 2008, 453:534-538.

4. Stefani G, Slack FJ: Small non-coding RNAs in animal development. Nat Rev Mol Cell Biol 2008, 9:2 I 9-230.

5. Okamura K, Lai EC: Endogenous small interfering RNAs in animals. Nat Rev Mol Cell Biol 2008, 9:673-678.

6. Peters L, Meister G: Argonaute proteins: mediators of RNA silencing. Mol Cell 2007, 26:6 I I-623.

7. Liu J, Carmell MA, Rivas FV, Marsden CG, Thomson JM, Song JJ, Hammond SM, Joshua-Tor L, Hannon G]: Argonaute2 is the catalytic engine of mammalian RNAi. Science 2004, 305: I437- I44I.

8. Eulalio A, Huntzinger $E$, Izaurralde $E:$ GWI82 interaction with Argonaute is essential for miRNA-mediated translational repression and mRNA decay. Nat Struct Mol Biol 2008, 15:346-353.

9. Landthaler M, Gaidatzis D, Rothballer A, Chen PY, Soll SJ, Dinic L, Ojo T, Hafner M, Zavolan M, Tuschl T: Molecular characterization of human Argonaute-containing ribonucleoprotein complexes and their bound target mRNAs. Rna 2008, 14:2580-96.

10. Rehwinkel J, Behm-Ansmant I, Gatfield D, Izaurralde E: A crucial role for GWI 82 and the DCPI:DCP2 decapping complex in miRNA-mediated gene silencing. Rna 2005, I I:1640-1647.

II. Behm-Ansmant I, Rehwinkel J, Doerks T, Stark A, Bork P, Izaurralde E: mRNA degradation by miRNAs and GW 182 requires both CCR4:NOT deadenylase and DCPI:DCP2 decapping complexes. Genes Dev 2006, 20:1885-1898.

12. Pillai RS, Bhattacharyya SN, Artus CG, Zoller T, Cougot N, Basyuk E, Bertrand E, Filipowicz W: Inhibition of translational initiation by Let-7 MicroRNA in human cells. Science 2005, 309: 1573-1576.

13. Bhattacharyya SN, Habermacher R, Martine U, Closs El, Filipowicz W: Relief of microRNA-mediated translational repression in human cells subjected to stress. Cell 2006, I 25: I I II-II 24 .

14. Jakymiw A, Lian S, Eystathioy T, Li S, Satoh M, Hamel JC, Fritzler MJ, Chan EK: Disruption of GW bodies impairs mammalian RNA interference. Nat Cell Biol 2005, 7: 1267-1274.

15. Liu J, Rivas FV, Wohlschlegel J, Yates JR 3rd, Parker R, Hannon GJ: A role for the P-body component GWI82 in microRNA function. Nat Cell Biol 2005, 7:|26I-1266.

16. Ding SW, Voinnet O: Antiviral immunity directed by small RNAs. Cell 2007, 130:413-426.

17. Gottwein E, Cullen BR: Viral and cellular microRNAs as determinants of viral pathogenesis and immunity. Cell Host Microbe 2008, 3:375-387

18. Yeung ML, Benkirane M, Jeang KT: Small non-coding RNAs, mammalian cells, and viruses: regulatory interactions? Retrovirology 2007, 4:74.

19. Han Y, Siliciano RF: Keeping quiet: microRNAs in HIV-I latency. Nat Med 2007, I 3:1 I 38-I I 40.

20. Weinberg MS, Morris KV: Are viral-encoded microRNAs mediating latent HIV-I infection? DNA Cell Biol 2006, 25:223-23I.

21. Triboulet R, Mari B, Lin YL, Chable-Bessia C, Bennasser Y, Lebrigand K, Cardinaud B, Maurin T, Barbry P, Baillat V, Reynes J, Corbeau P,
Jeang KT, Benkirane M: Suppression of microRNA-silencing pathway by HIV-I during virus replication. Science 2007, 315:1579-1582.

22. Huang J, Wang F, Argyris E, Chen K, Liang Z, Tian H, Huang W, Squires $\mathrm{K}$, Verlinghieri G, Zhang $\mathrm{H}$ : Cellular microRNAs contribute to HIV-I latency in resting primary CD4+ T lymphocytes. Nat Med 2007, 13:124I-1247.

23. Ahluwalia JK, Khan SZ, Soni K, Rawat P, Gupta A, Hariharan M, Scaria V, Lalwani M, Pillai B, Mitra D, Brahmachari SK: Human cellular microRNA hsa-miR-29a interferes with viral nef protein expression and HIV-I replication. Retrovirology 2008, 5: II 7.

24. Beckham C], Parker R: $\mathbf{P}$ bodies, stress granules, and viral life cycles. Cell Host Microbe 2008, 3:206-2I2.

25. Griffith JL, Coleman LE, Raymond AS, Goodson SG, Pittard WS, Tsui C, Devine SE: Functional genomics reveals relationships between the retrovirus-like Tyl element and its host Saccharomyces cerevisiae. Genetics 2003, 164:867-879.

26. Devine SE, Boeke JD: Integration of the yeast retrotransposon Tyl is targeted to regions upstream of genes transcribed by RNA polymerase III. Genes Dev 1996, 10:620-633.

27. Beliakova-Bethell N, Beckham C, Giddings TH Jr, Winey M, Parker R, Sandmeyer S: Virus-like particles of the Ty3 retrotransposon assemble in association with P-body components. Rna 2006, I 2:94-I0I.

28. Beckham CJ, Light HR, Nissan TA, Ahlquist P, Parker R, Noueiry A: Interactions between brome mosaic virus RNAs and cytoplasmic processing bodies. J Virol 2007, 81 : 9759-9768.

29. Gallois-Montbrun S, Kramer B, Swanson CM, Byers H, Lynham S, Ward M, Malim MH: Antiviral protein APOBEC3G localizes to ribonucleoprotein complexes found in $\mathrm{P}$ bodies and stress granules. J Virol 2007, 8I:2165-2178.

30. Wichroski MJ, Robb GB, Rana TM: Human retroviral host restriction factors $A P O B E C 3 G$ and $A P O B E C 3 F$ localize to mRNA processing bodies. PLoS Pathog 2006, 2:e4I.

31. Chu CY, Rana TM: Translation repression in human cells by microRNA-induced gene silencing requires RCK/p54. PLoS Biol 2006, 4:e210.

32. Goff SP: Host factors exploited by retroviruses. Nat Rev Microbiol 2007, 5:253-263.

33. Brass AL, Dykxhoorn DM, Benita Y, Yan N, Engelman A, Xavier RJ, Lieberman J, Elledge SJ: Identification of host proteins required for HIV infection through a functional genomic screen. Science 2008, 31 9:92I-926.

34. König R, Zhou Y, Elleder D, Diamond TL, Bonamy GM, Irelan JT, Chiang CY, Tu BP, De Jesus PD, Lilley CE, Seidel S, Opaluch AM, Caldwell JS, Weitzman MD, Kuhen KL, Bandyopadhyay S, Ideker T, Orth AP, Miraglia LJ, Bushman FD, Young JA, Chanda SK: Global analysis of host-pathogen interactions that regulate early-stage HIV-I replication. Cell 2008, 135:49-60.

35. Lama J, Planelles V: Host factors influencing susceptibility to HIV infection and AIDS progression. Retrovirology 2007, 4:52.

36. Chun TW, Engel D, Berrey MM, Shea T, Corey L, Fauci AS: Early establishment of a pool of latently infected, resting CD4(+) T cells during primary HIV-I infection. Proc Natl Acad Sci USA 1998, 95:8869-8873.

37. Finzi D, Hermankova M, Pierson T, Carruth LM, Buck C, Chaisson RE, Quinn TC, Chadwick K, Margolick J, Brookmeyer R, Gallant J, Markowitz M, Ho DD, Richman DD, Siliciano RF: Identification of a reservoir for HIV-I in patients on highly active antiretroviral therapy. Science 1997, 278:1295-1300.

38. Marcello A: Latency: the hidden HIV-I challenge. Retrovirology 2006, 3:7.

39. Lassen K, Han Y, Zhou Y, Siliciano J, Siliciano RF: The multifactorial nature of HIV-I latency. Trends Mol Med 2004, I 0:525-53I.

40. Jordan A, Bisgrove $D$, Verdin E: HIV reproducibly establishes a latent infection after acute infection of $T$ cells in vitro. Embo J 2003, 22: 1868-1877.

4I. Han Y, Lin YB, An W, Xu J, Yang HC, O'Connell K, Dordai D, Boeke JD, Siliciano JD, Siliciano RF: Orientation-dependent regulation of integrated HIV-I expression by host gene transcriptional readthrough. Cell Host Microbe 2008, 4:134-146.

42. De Marco A, Biancotto C, Knezevich A, Maiuri P, Vardabasso C, Marcello A: Intragenic transcriptional cis-activation of the human immunodeficiency virus I does not result in allele-specific inhibition of the endogenous gene. Retrovirology 2008, 5:98. 
43. Weinberger LS, Burnett JC, Toettcher JE, Arkin AP, Schaffer DV: Stochastic gene expression in a lentiviral positive-feedback loop: HIV-I Tat fluctuations drive phenotypic diversity. Cell 2005, 122:169-182.

44. Williams SA, Chen LF, Kwon H, Ruiz-Jarabo CM, Verdin E, Greene WC: NF-kappaB p50 promotes HIV latency through HDAC recruitment and repression of transcriptional initiation. Embo J 2006, 25: I39-149.

45. Kim YK, Bourgeois CF, Pearson R, Tyagi M, West MJ, Wong J, Wu SY, Chiang CM, Karn J: Recruitment of TFIIH to the HIV LTR is a rate-limiting step in the emergence of HIV from latency. Embo f 2006, 25:3596-3604.

46. Tyagi M, Karn J: CBF-I promotes transcriptional silencing during the establishment of HIV-I latency. Embo J 2007, 26:4985-4995

47. Treand C, du Chene I, Bres V, Kiernan R, Benarous R, Benkirane M, Emiliani S: Requirement for SWI/SNF chromatin-remodeling complex in Tat-mediated activation of the HIV-I promoter. Embo J 2006, 25:1690-1699.

48. du Chéné I, Basyuk E, Lin YL, Triboulet R, Knezevich A, Chable-Bessia C, Mettling C, Baillat V, Reynes J, Corbeau P, Bertrand E, Marcello A, Emiliani S, Kiernan R, Benkirane M: Suv39HI and HP I gamma are responsible for chromatin-mediated HIV-I transcriptional silencing and post-integration latency. Embo J 2007, 26:424-435.

49. Marban C, Suzanne S, Dequiedt F, de Walque S, Redel L, Van Lint C, Aunis D, Rohr O: Recruitment of chromatin-modifying enzymes by CTIP2 promotes HIV-I transcriptional silencing. Embo J 2007, 26:4I2-423.

50. Pearson R, Kim YK, Hokello J, Lassen K, Friedman J, Tyagi M, Karn J: Epigenetic silencing of human immunodeficiency virus (HIV) transcription by formation of restrictive chromatin structures at the viral long terminal repeat drives the progressive entry of HIV into latency. J Virol 2008, 82: | 229|- 2303.

5I. Sadowski I, Lourenco P, Malcolm T: Factors controlling chromatin organization and nucleosome positioning for establishment and maintenance of HIV latency. Curr HIV Res 2008, 6:286-295

52. Pomerantz RJ, Seshamma T, Trono D: Efficient replication of human immunodeficiency virus type I requires a threshold level of Rev: potential implications for latency. J Virol 1992, 66:1809-1813.

53. Hermankova M, Siliciano JD, Zhou Y, Monie D, Chadwick K, Margolick JB, Quinn TC, Siliciano RF: Analysis of human immunodeficiency virus type I gene expression in latently infected resting CD4+ T lymphocytes in vivo. J Virol 2003, 77:7383-7392.

54. Ciuffi A, Bleiber G, Muñoz M, Martinez R, Loeuillet C, Rehr M, Fischer M, Günthard HF, Oxenius A, Meylan P, Bonhoeffer S, Trono D, Telenti $A$ : Entry and transcription as key determinants of differences in CD4 T-cell permissiveness to human immunodeficiency virus type I infection. I Virol 2004, 78:10747-10754.

55. Qian S, Zhong X, Yu L, Ding B, de Haan P, Boris-Lawrie K: HIV-I Tat RNA silencing suppressor activity is conserved across kingdoms and counteracts translational repression of HIV-I. Proc Natl Acad Sci USA 2009, 106:605-610.

56. Bennasser Y, Le SY, Benkirane M, Jeang KT: Evidence that HIV-I encodes an siRNA and a suppressor of RNA silencing. Immunity 2005, 22:607-619.

57. Haasnoot J, de Vries W, Geutjes EJ, Prins M, de Haan P, Berkhout B: The Ebola virus VP35 protein is a suppressor of RNA silencing. PLoS Pathog 2007, 3:e86.

58. Schnettler E, de Vries W, Hemmes H, Haasnoot J, Kormelink R, Goldbach R, Berkhout $B$ : The NS3 protein of rice hoja blanca virus complements the RNAi suppressor function of HIV-I Tat. EMBO Rep 2009, 10:258-63.

59. Alexaki A, Liu Y, Wigdahl B: Cellular reservoirs of HIV-I and their role in viral persistence. Curr HIV Res 2008, 6:388-400.

60. Palliser D, Chowdhury D, Wang QY, Lee SJ, Bronson RT, Knipe DM, Lieberman ]: An siRNA-based microbicide protects mice from lethal herpes simplex virus 2 infection. Nature 2006, 439:89-94.

6I. Krutzfeldt J, Rajewsky N, Braich R, Rajeev KG, Tuschl T, Manoharan $M$, Stoffel M: Silencing of microRNAs in vivo with 'antagomirs'. Nature 2005, 438:685-689.

62. Zimmermann TS, Lee AC, Akinc A, Bramlage B, Bumcrot D, Fedoruk MN, Harborth J, Heyes JA, Jeffs LB, John M, Judge AD, Lam K, McClin- tock K, Nechev LV, Palmer LR, Racie T, Röhl I, Seiffert S, Shanmugam S, Sood V, Soutschek J, Toudjarska I, Wheat AJ, Yaworski E, Zedalis W, Koteliansky V, Manoharan M, Vornlocher HP, MacLachlan I: RNAi-mediated gene silencing in non-human primates. Nature 2006, 44 I: I I I-I I 4 .

63. Newman EN, Holmes RK, Craig HM, Klein KC, Lingappa JR, Malim $\mathrm{MH}$, Sheehy AM: Antiviral function of APOBEC3G can be dissociated from cytidine deaminase activity. Curr Biol 2005, I5:166-170.

64. Molle D, Maiuri P, Boireau S, Bertrand E, Knezevich A, Marcello A, Basyuk E: A real-time view of the TAR:Tat:P-TEFb complex at HIV-I transcription sites. Retrovirology 2007, 4:36.

65. Boireau S, Maiuri P, Basyuk E, de la Mata M, Knezevich A, PradetBalade B, Backer V, Kornblihtt A, Marcello A, Bertrand E: The transcriptional cycle of HIV-I in real-time and live cells. J Cell Biol 2007, 179:291-304.

66. Jacquenet S, Mereau A, Bilodeau PS, Damier L, Stoltzfus CM, Branlant C: A second exon splicing silencer within human immunodeficiency virus type $I$ tat exon 2 represses splicing of Tat mRNA and binds protein hnRNP H. I Biol Chem 200I, 276:40464-40475.
Publish with Bio Med Central and every scientist can read your work free of charge

"BioMed Central will be the most significant development for disseminating the results of biomedical research in our lifetime. "

Sir Paul Nurse, Cancer Research UK

Your research papers will be:

- available free of charge to the entire biomedical community

- peer reviewed and published immediately upon acceptance

- cited in PubMed and archived on PubMed Central

- yours - you keep the copyright

Submit your manuscript here:

http://www.biomedcentral.com/info/publishing_adv.asp 